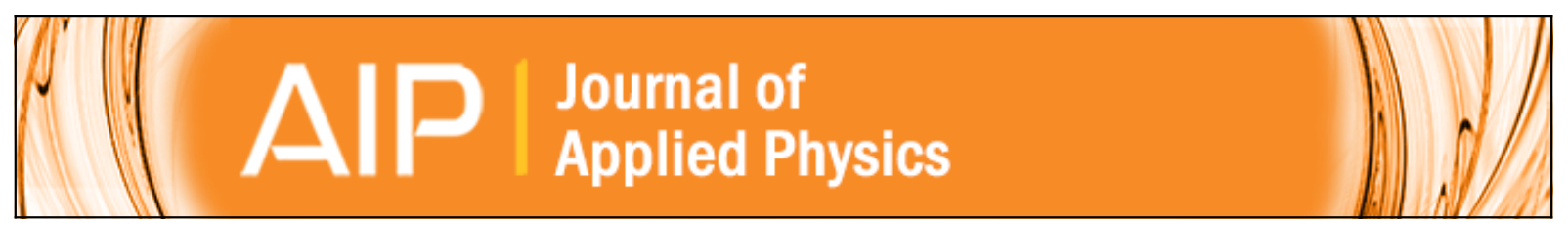

\title{
Room temperature p-type conductivity and coexistence of ferroelectric order in ferromagnetic Li doped ZnO nanoparticles
}

Saif Ullah Awan, S. K. Hasanain, D. H. Anjum, M. S. Awan, and Saqlain A. Shah

Citation: Journal of Applied Physics 116, 164109 (2014); doi: 10.1063/1.4900413

View online: http://dx.doi.org/10.1063/1.4900413

View Table of Contents: http://scitation.aip.org/content/aip/journal/jap/116/16?ver=pdfcov

Published by the AIP Publishing

\section{Articles you may be interested in}

Room-temperature ferromagnetism in hydrogenated $\mathrm{ZnO}$ nanoparticles

J. Appl. Phys. 115, 033902 (2014); 10.1063/1.4862306

Ferromagnetism in Li doped $\mathrm{ZnO}$ nanoparticles: The role of interstitial $\mathrm{Li}$

J. Appl. Phys. 112, 103924 (2012); 10.1063/1.4767364

The origin of magnetism in perovskite ferroelectric $\mathrm{ABO}$ nanoparticles $(\mathrm{A}=\mathrm{K}, \mathrm{Li} ; \mathrm{B}=\mathrm{Ta}, \mathrm{Nb}$ or $\mathrm{A}=\mathrm{Ba}, \mathrm{Sr}, \mathrm{Pb} ; \mathrm{B}=\mathrm{Ti})$

J. Appl. Phys. 112, 053907 (2012); 10.1063/1.4748319

Multiferroic response of nanocrystalline lithium niobate

J. Appl. Phys. 111, $07 D 907$ (2012); 10.1063/1.3673434

Room temperature long range ferromagnetic ordering in (BiFeO3)1-x (PbTiO3)x nanocrystallites J. Appl. Phys. 109, 123911 (2011); 10.1063/1.3592281

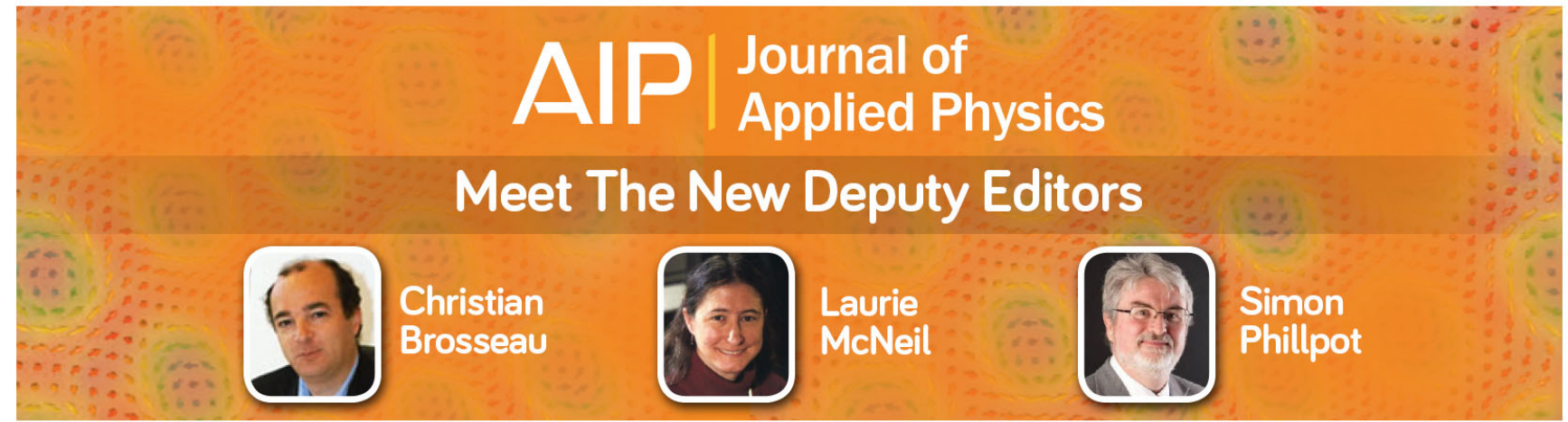




\title{
Room temperature $p$-type conductivity and coexistence of ferroelectric order in ferromagnetic Li doped $\mathrm{ZnO}$ nanoparticles
}

\author{
Saif Ullah Awan, ${ }^{1,2, a)}$ S. K. Hasanain, ${ }^{1}$ D. H. Anjum, ${ }^{3}$ M. S. Awan, ${ }^{4}$ and Saqlain A. Shah ${ }^{5}$ \\ ${ }^{1}$ Department of Physics, Quaid-i-Azam University, Islamabad 45320, Pakistan \\ ${ }^{2}$ Department of Physics, COMSATS Institute of Information Technology, Islamabad 44000, Pakistan \\ ${ }^{3}$ Advanced Nanofabrication, Imaging and Characterization Core Lab (ANIC), King Abdullah University \\ of Science \& Technology (KAUST), Thuwal, Makkah 23599-6900, Kingdom of Saudi Arabia \\ ${ }^{4}$ Center for Micro and Nano Devices, Department of Physics, COMSATS Institute of Information Technology, \\ Islamabad 44000, Pakistan \\ ${ }^{5}$ Department of Materials Science \& Engineering, University of Washington, Seattle, Washington 98195, USA
}

(Received 31 August 2014; accepted 13 October 2014; published online 29 October 2014)

\begin{abstract}
Memory and switching devices acquired new materials which exhibit ferroelectric and ferromagnetic order simultaneously. We reported multiferroic behavior in $\mathrm{Zn}_{1-\mathrm{y}} \mathrm{Li}_{\mathrm{y}} \mathrm{O}(0.00 \leq \mathrm{y} \leq 0.10)$ nanoparticles. The analysis of transmission electron micrographs confirmed the hexagonal morphology and wurtzite crystalline structure. We investigated $p$-type conductivity in doped samples and measured hole carriers in range $2.4 \times 10^{17} / \mathrm{cc}$ to $7.3 \times 10^{17} / \mathrm{cc}$ for different $\mathrm{Li}$ contents. We found that hole carriers are responsible for long range order ferromagnetic coupling in Li doped samples. Room temperature ferroelectric hysteresis loops were observed in $8 \%$ and $10 \% \mathrm{Li}$ doped samples. We demonstrated ferroelectric coercivity (remnant polarization) $2.5 \mathrm{kV} / \mathrm{cm}\left(0.11 \mu \mathrm{C} / \mathrm{cm}^{2}\right)$ and $2.8 \mathrm{kV} / \mathrm{cm}$ $\left(0.15 \mu \mathrm{C} / \mathrm{cm}^{2}\right)$ for $\mathrm{y}=0.08$ and $\mathrm{y}=0.10$ samples. We propose that the mechanism of $\mathrm{Li}$ induced ferroelectricity in $\mathrm{ZnO}$ is due to indirect dipole interaction via hole carriers. We investigated that if the sample has hole carriers $\geq 5.3 \times 10^{17} / \mathrm{cc}$, they can mediate the ferroelectricity. Ferroelectric and ferromagnetic measurements showed that higher electric polarization and larger magnetic moment is attained when the hole concentration is larger and vice versa. Our results confirmed the hole dependent coexistence of ferromagnetic and ferroelectric behavior at room temperature, which provide potential applications for switchable and memory devices. (C) 2014 AIP Publishing LLC.
\end{abstract}

[http://dx.doi.org/10.1063/1.4900413]

\section{INTRODUCTION}

Increasing demand of stable nanoscale memory elements in the field of spintronics have led to a renewed interest in exploring the coexistence of ferromagnetic and ferroelectric order in a single phase. ${ }^{1}$ Although conventional magnetoelectric routes often result in weaker responses, there is a highly growing interest of researchers in identifying new mechanisms for understanding the simultaneous existence of ferromagnetic and ferroelectric behaviors. ${ }^{2}$ Multiferroic materials can exhibit ferromagnetic and ferroelectric orders simultaneously in the same phase. ${ }^{3}$ This means that they have a spontaneous magnetization that can be reoriented by an applied magnetic field, as well as a spontaneous polarization that can be reoriented by an applied electric field. ${ }^{4}$ In these multiferroics, one can expect the coupling between the magnetic and electric properties as well as their control by the application of magnetic and/or electric fields. ${ }^{5}$ Multiferroic have immense applications in data storage, spintronics, spin valves, quantum electromagnets, random access memory, and nonvolatile memory devices. ${ }^{6}$ There has been a renewed interest in exploring the multiferroic materials after theoretical breakthrough in understanding the co-existence of magnetic and electric ordering. ${ }^{4}$ Furthermore, with the exception of a few compounds, such

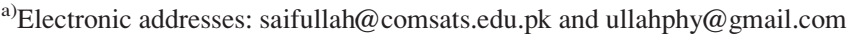

as some boracites, ${ }^{7}$ manganites, ${ }^{8}$ and magnetite, ${ }^{9}$ most of the multiferroics reported so far are anti-ferromagnetic having no spontaneous magnetization (or ferromagnetic with very low Curie temperature) in which a prominent response to the applied fields cannot be expected. ${ }^{10}$

The emission of light has been demonstrated in heterojunction light emitting diodes using $n$-type $\mathrm{ZnO}$ and various other materials for the $p$-layer. ${ }^{11}$ However, the development of higher-efficiency, homojunction devices $^{12}$ has been limited due to the lack of reliable $p$-type $\mathrm{ZnO}$, which is necessary to produce $p-n$ structures. This problem has received considerable attention with numerous reports ${ }^{13}$ on growth as well as theoretical predictions of $p$-type doped $\mathrm{ZnO}$ systems. It is well known that $\mathrm{ZnO}$, in undoped form, usually exhibits strong $n$-type conductivity, which has been ascribed to the native (e.g., oxygen vacancy) defects. ${ }^{14}$ Theoretical investigations ${ }^{15}$ have predicted that $p$-type conductivity is achievable if alkali metals are doped into the $\mathrm{Zn}$ sites. Lithium ions $\left(\mathrm{Li}^{1+}\right)$ are considered as potential dopants because of their smaller size and charge miss-match compared to zinc $\left(\mathrm{Zn}^{2+}\right)$ ions. ${ }^{14}$ The realization of $p$-type $\mathrm{ZnO}$ has so far been difficult due to the amphoteric behavior of Li. Various mechanisms have been suggested to account for the difficulty in achieving $p$-type layers including self-compensation, resulting in Fermi level pinning near the mid-gap, lattice relaxation effects producing deep acceptor levels, or low solubility of the target dopant. ${ }^{16}$ In the few cases where successful $p$-type doping 
has been reported, the large values of the hole mobility or concentration are questionable. Behavior of $p$-type ${ }^{17,18}$ and $n$-type ${ }^{19}$ conductivity in $\mathrm{Li}$ doped $\mathrm{ZnO}$ thin films have been reported earlier. As a result of these conflicting reports, questions as to whether stable $p$-type $\mathrm{Li}$ doped $\mathrm{ZnO}$ systems, even exists or not, are still debatable.

$\mathrm{Li}$ doped $\mathrm{ZnO}$ ceramics, ${ }^{14,20,21}$ films, $^{22}$ and nanorods ${ }^{23}$ are reported to exhibit ferroelectric behavior, while the nature of conductivity ( $n / p$-type) has not been reported there. ${ }^{14,20-23}$ Onwards till now, to the best of our knowledge, there is no report of ferroelectric hysteresis study of $\mathrm{Li}$ doped $\mathrm{ZnO}$ nanoparticles where finite size effects are also expected to play a significant role in the electrical properties. Furthermore, in reports ${ }^{17-19} \mathrm{p} / \mathrm{n}$-type conductivity of $\mathrm{Li}$ doped $\mathrm{ZnO}$ systems was observed, but we did not find any indication of ferromagnetism or ferroelectricity. Another ambiguity is, in reports $^{18,24,25} p$-type room temperature ferromagnetism was observed but not ferroelectricity. Overall, Li doped $\mathrm{ZnO}$ ferroelectric behavior does exist, but it is not clear whether the materials under study are ferromagnetic too, and if so, to what extent. Does the increase of the magnetic moment correlate with an increase of the electric polarization, or is it contrary wise? Furthermore, the mechanism of how this ferroelectricity is induced in $\mathrm{Li}$ doped $\mathrm{ZnO}$ systems is not fully understood. Generally, when host atoms are replaced by small substitutional ions, these ions may be located in off-centered positions and thus locally induce permanent electric dipole moments. This scenario should lead to the appearance of spontaneous polarization. ${ }^{14,26}$ The main question here is, what makes the dipoles to become ferroelectrically ordered? Recently, Ruderman-Kittel-Kasuya-Yosida (RKKY) type indirect interaction of impurities dipole via free charge carriers has been reported for understanding the nature of ferroelectricity in nonperovskite oxide systems. ${ }^{27-30}$ It has been reported theoretically that the usual semiconducting concentration of charge carriers of about $10^{17} \mathrm{~cm}^{-3}$ is sufficient for the realization of ferroelectric effects in the $\mathrm{Li}$ doped $\mathrm{ZnO}$ system. ${ }^{27}$

We have reported ${ }^{31}$ the role of interstitial $\mathrm{Li}$ on room temperature ferromagnetic behavior in $\mathrm{ZnO}$ nanoparticles. In this article, we carried out microstructural and electrical properties of the same system. Here, we report the conductivity type, resistivity, and charge carrier density in nanoparticles. The function of the holes in correlating the ferroelectric transition temperatures and magnetic saturation polarization will be presented. We shall investigate how the hole carriers are correlated with ferroelectric and ferromagnetic moments and what is the co-relation of their polarization in $\mathrm{Li}$ doped $\mathrm{ZnO}$ nanoparticles. The role of holes in electric polarization and ferroelectric transition temperature will be understood. The mechanism of ferromagnetic and ferroelectric orders in this oxide system will be discussed. We expect that the results of our studies will add to the basic understanding of the roles played by $\mathrm{Li}$ and its associated defects (i.e., holes) in stabilizing $p$-type conductivity in multiferroic systems.

\section{EXPERIMENTAL PROCEDURE}

The synthesis procedure of these $\mathrm{Li}$ doped $\mathrm{ZnO}$ $\left[\mathrm{Zn}_{1-y} \mathrm{Li}_{y} \mathrm{O}(y=0.00,0.02,0.04,0.06,0.08\right.$, and 0.10$\left.)\right]$ nanoparticles has been reported earlier. ${ }^{31}$ Microstructures were obtained using FEI Company's Titan G260-300CT transmission electron microscopy (TEM). The bright field (BF) micrographs were acquired at around $70000 \mathrm{X}$ as well as $500000 \mathrm{X}$ for low resolution and high resolution TEM analysis, respectively. Fast-Fourier Transform (FFT) was applied to determine the d-spacing. ${ }^{32}$ The samples were further analyzed with the technique of Electron Energy-Loss Spectroscopy (EELS) using Gatan, Inc.'s TridiemTM energyfilter for the determination of their elemental composition. The EELS spectra were collected by keeping the energy of primary electrons to $300 \mathrm{KeV}$ and the dispersion to $0.5 \mathrm{eV}$ per channel of energy-filter in EELS-mode. ${ }^{32}$ Commercial HMS5500 van der Pauw system was used for Hall measurements. A current of $100 \mu \mathrm{A}$ and magnetic field of $0.55 \mathrm{~T}$ were fixed for all samples. Most materials measured by a Hall effect measurement system require that contacts be made in the corners of the sample to improve electrical conductivity. Material we used for making contacts is indium/tin, i.e., InSn compound which is $95 \%$ indium and 5\% tin. This will help the spring clip board pin make better contacts. These electrical measurements were conducted on squared pelletized samples of $10 \times 10 \mathrm{~mm}$ and thickness $1 \mathrm{~mm}$. Ferroelectric polarization hysteresis measurements were obtained using a RT-66A ferroelectric system using circular pelletized samples of diameter $10 \mathrm{~mm}$ and thickness $1 \mathrm{~mm}$. For electrical measurements, all samples were compacted uniaxially into pellets under identical conditions (e.g., 6-ton pressure) so as to retain the same density over the entire composition range thereby minimizing the possible variations in the inter-grain resistivity contributions. A thin layer of silver paste was used for making parallel plate capacitor geometry for ferroelectric measurements of all samples.

\section{EXPERIMENTAL RESULTS AND DISCUSSION}

\section{A. Morphology and microstructural analysis}

Fig. 1(a) shows the low magnification BF TEM image of pure $\mathrm{ZnO}$ nanoparticles. We perceived the agglomeration of nanoparticles, as the specimens were post annealed to enhance the crystallinity. We investigated the size of the $\mathrm{ZnO}$ nanoparticles in the range of 5-50 nm (histogram not presented here). Fig. 1(b) demonstrated High resolution transmission electron microscope (HRTEM) micrograph of the undoped $\mathrm{ZnO}$ sample. After the investigation of HRTEM images, we found the hexagonal morphology and polycrystalline structure in the absence of amorphous part. Fig. 1(c) presents the fast Fourier transform (FFT) image of the $\mathrm{ZnO}$ sample during measurement. Fig. 1(d) represents the selected area electron diffraction (SAED) patterns of different planes by applying hough Transfrom to FFT. The $d$-values were calculated from these SAED patterns for $\mathrm{ZnO}$ sample. Fig. 2(a) shows low resolution BF-TEM micrographs of $\mathrm{Zn}_{0.96} \mathrm{Li}_{0.04} \mathrm{O}$ sample. We observed the particle sized distribution in the range $10-60 \mathrm{~nm}$ (histogram not presented here). We acquired HRTEM image (Fig. 2(b)), FFT micrograph of the HRTEM (Fig. 2(c)), and SAED (Fig. 2(d)) measurement of $\mathrm{Zn}_{0.96} \mathrm{Li}_{0.04} \mathrm{O}$ sample. From the diffracted pattern of $\mathrm{Zn}_{0.96} \mathrm{Li}_{0.04} \mathrm{O}$, we calculated $d$-values and found that all 

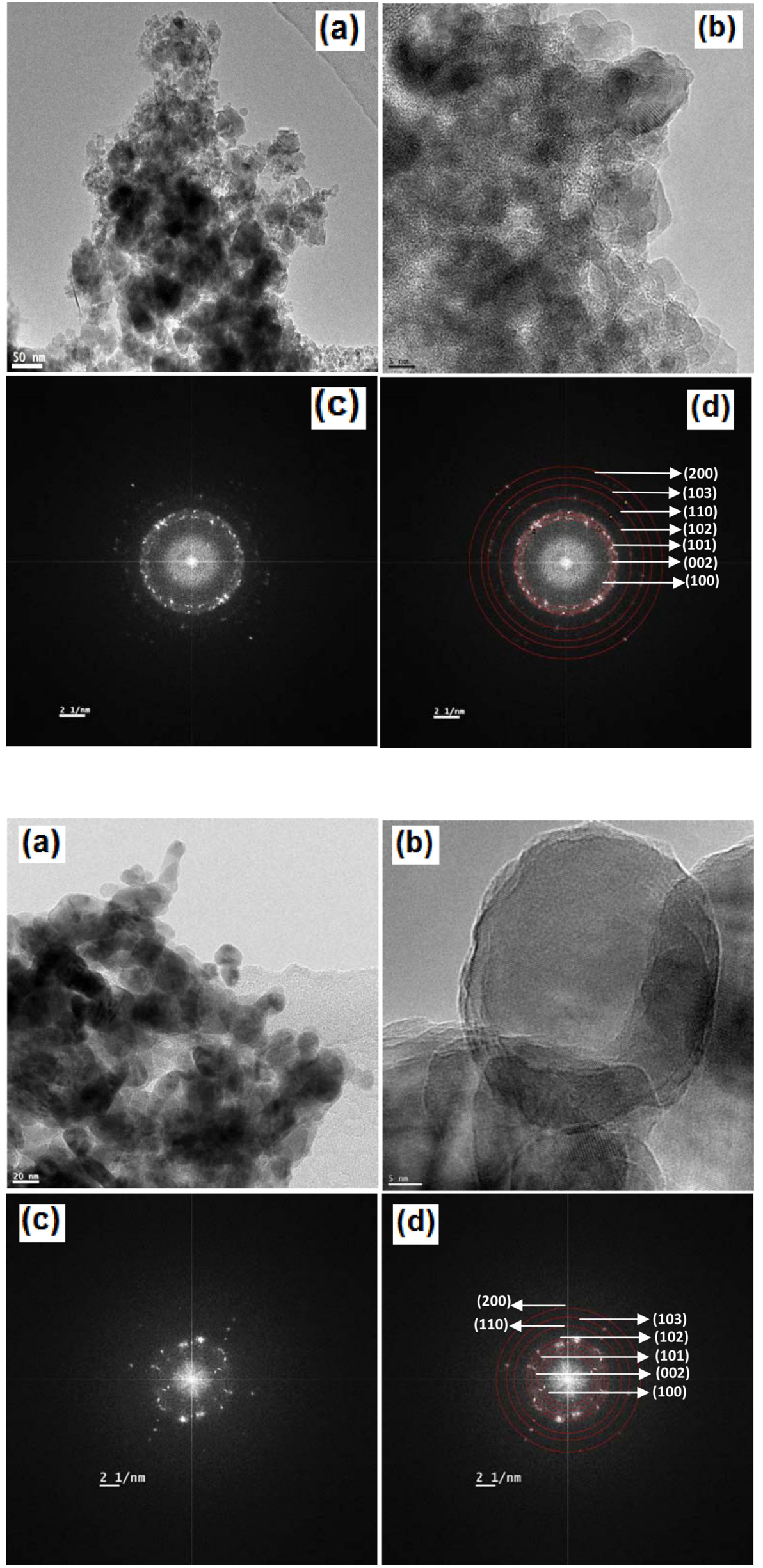

FIG. 1. (a) BF-TEM micrograph at low magnification (b) HR-TEM image (c) FFT image of the HR-TEM and (d) Hough Transform of $\mathrm{ZnO}$ nanoparticles sample.
FIG. 2. (a) BF-TEM micrograph at low magnification (b) HR-TEM image (c) FFT image of the HR-TEM and (d) Hough Transform of $\mathrm{Zn}_{0.96} \mathrm{Li}_{0.04} \mathrm{O}$ nanoparticles sample. 
planes corresponded to the $\mathrm{ZnO}$ (JCPDS file no. 36-1451) crystalline structure. Hence, we observed the wurtzite crystalline structure, which also confirmed the absence of secondary or any metallic phases in samples. These microstructural measurements of samples clearly showed hexagonal (SG $P 63 m c, a=0.32 \mathrm{~nm}, c=0.52 \mathrm{~nm}$ ) crystalline structure.

These $d$-values of above compositions are in good agreement with the XRD data reported earlier. ${ }^{31}$ It can be noticed that $4 \% \mathrm{Li}$ doped sample has smaller $d$-spacing than $\mathrm{ZnO}$ sample. This observation suggests contraction of the unit cell which is due to the presence of more Li ions occupying substitutional sites. Decrease in lattice parameters is expected when Li substitutes $\mathrm{Zn}$, while the lattice parameter will increase when $\mathrm{Li}$ occupies interstitial sites. ${ }^{25}$ For $\mathrm{Li}$ doped nanoparticles, we reported ${ }^{31}$ that the contraction of lattice parameters was observed for $4 \% \mathrm{Li}$ incorporation, as $\mathrm{Li}$ incorporated into substitutional sites $\left(\mathrm{Li}_{\mathrm{Zn}}\right)$. In contrast, lattice parameters increase for 2,8 , and 10 at. \% Li samples where Li occupy the interstitial sites. Here, we have consistently observed using TEM, that lattice parameters increased for $y=0.02$ (TEM data not shown) and decreased for $\mathrm{y}=0.04$ samples as compared to $\mathrm{ZnO}$ samples. We got similar results via XRD earlier ${ }^{31}$ on these samples.

Energy filtered transmission electron microscopy (EFTEM) measurements were performed to detect and map $\mathrm{Li}$ in the samples. Fig. 3(a) shows the EFTEM mode low resolution micrographs of $\mathrm{Zn}_{0.98} \mathrm{Li}_{0.02} \mathrm{O}$ sample. Fig. 3(b) shows the $\mathrm{Li}$ maps of $\mathrm{Zn}_{0.98} \mathrm{Li}_{0.042}$ sample that reveals that $\mathrm{Li}$ was distributed uniformly and homogeneously into the $\mathrm{ZnO}$ crystal structure without forming any clusters. The presence of $\mathrm{Li}$ in the lattice of $\mathrm{ZnO}$ was confirmed by EELS measurements. We measured EELS spectrum for $\mathrm{y}=0.02$ and noticed the $\mathrm{Zn}-\mathrm{L}_{23}$ and $\mathrm{O}-\mathrm{K}$ edges in the scan range $400-1400 \mathrm{eV}$, as shown in Fig. 4(a), while Fig. 4(b) shows the lower scan range $50-180 \mathrm{eV}$ spectra in which $\mathrm{Li}-\mathrm{K}$ edge and $\mathrm{Zn}-\mathrm{M}_{23}$ edge are clearly visible. Figs. 4(a) and 4(b) confirm the coexistence of $\mathrm{Zn}$ and $\mathrm{Li}$ along with $\mathrm{O}$ ions. A shoulder present in the near edge structure of $\mathrm{Li}-\mathrm{K}$ and the $\mathrm{Li}$ intensity ratio confirm Li to be in +1 valence state, as expected for the doping of $\mathrm{Li}$ in the $\mathrm{ZnO}$ structure. The broad peak of $\mathrm{Zn}-\mathrm{L} 23$ come from the transitions of $\mathrm{Zn} 2 \mathrm{p} 3 / 2$ and $2 \mathrm{p} 1 / 2$ core electrons, split by the spin-orbit interaction of the $\mathrm{Zn} 2 \mathrm{p}$ core level, to an occupied $3 \mathrm{~d}$ level highly hybridized with oxygen
O2p orbital, respectively. ${ }^{33}$ The main band at $530 \mathrm{eV}$ derives from the electron transition of $\mathrm{O} 1 \mathrm{~s}$ to $2 \mathrm{p}$, which reflects the occupancy of the electrons in the p-shell of the oxygen atoms. The shoulder of O-K comes from the transition of the $1 \mathrm{~s}$ electron to the higher-energy continuum level in the crystal field. $^{33,34}$ These observations confirm the nanoparticles to have a homogeneous distribution of $\mathrm{Li}$ in $\mathrm{ZnO}$ matrix. No other element was detected in EELS spectra. These EFTEM and EELS findings also confirmed the absence of metallic or secondary phases and any types of precipitates.

\section{B. Hall measurements}

Due to the profound significance and extensive debate about the carriers and their dependence on the dopant, Hall measurements were conducted on a series of $\mathrm{Zn}_{1-\mathrm{y}} \mathrm{Li}_{\mathrm{y}} \mathrm{O}(0.00 \leq \mathrm{y} \leq 0.10)$ nanoparticles. The Hall measurements were compiled by adopting both positive and negative currents and magnetic fields, and the results were averaged after 5 readings for each sample. The room temperature Hall measurements, e.g., sign (type) of charge carriers, resistivity, mobility, and carrier concentrations for a series of nanoparticle samples are listed in Table I. It is however apparent from the Hall data that the dominant behavior in $\mathrm{Li}$ doped compositions is $p$-type (hole) conduction. The undoped $\mathrm{ZnO}$ sample showed $n$-type conductivity with carrier concentration $4.4 \times 10^{15} / \mathrm{cc}$, which may be attributed to the presence of more oxygen vacancies. The positive conductivity confirms that the Li doped compositions are $p$-type behavior with carrier concentration range $2.4 \times 10^{17} / \mathrm{cc}$ to $7.3 \times 10^{17} / \mathrm{cc}$. The $p$-type conductivity in doped sample may be due to the contribution of additional holes from Li doping interstitially or substitutionally. Contradictionally, $p$-type $\mathrm{e}^{35}$ and $n$-type ${ }^{36}$ behavior of undoped $\mathrm{ZnO}$ thin films has been confirmed previously. Similarly, $p$-type $\mathrm{e}^{17,18}$ and $n$-type ${ }^{19}$ conductivity in $\mathrm{Li}$ doped $\mathrm{ZnO}$ thin films has been reported. The $p$-type Hall resistivity of our pelletized samples is comparable with pelletized $\mathrm{Li}$ doped $\mathrm{ZnO}$ nanorods. ${ }^{18}$

The trend of hole concentrations and Hall resistivity with increasing Li concentration are plotted in Fig. 5. We noticed that the trend of hole concentration values passes through a maximum for $\mathrm{y}=0.02,0.08$, and 0.010 samples. It is noticeable that the intermediate compositions $(y=0.04$
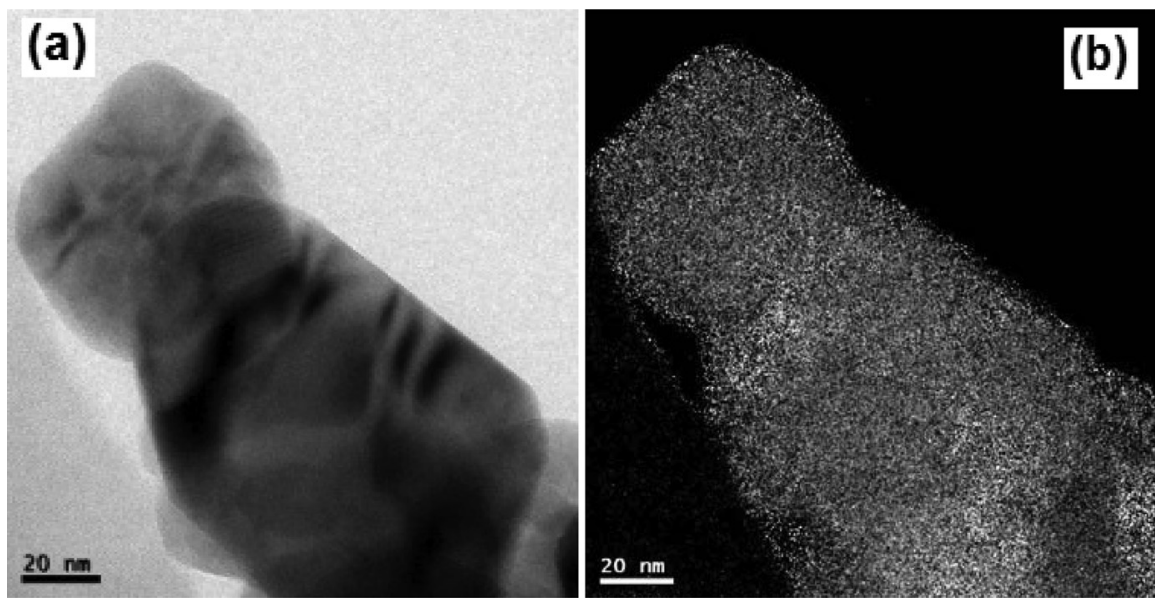

FIG. 3. (a) BF micrograph and (b) EFHRTEM for Li mapping acquired from $\mathrm{Li}-\mathrm{K}$ edge signal of $\mathrm{Zn}_{0.98} \mathrm{Li}_{0.02} \mathrm{O}$ nanoparticles. 

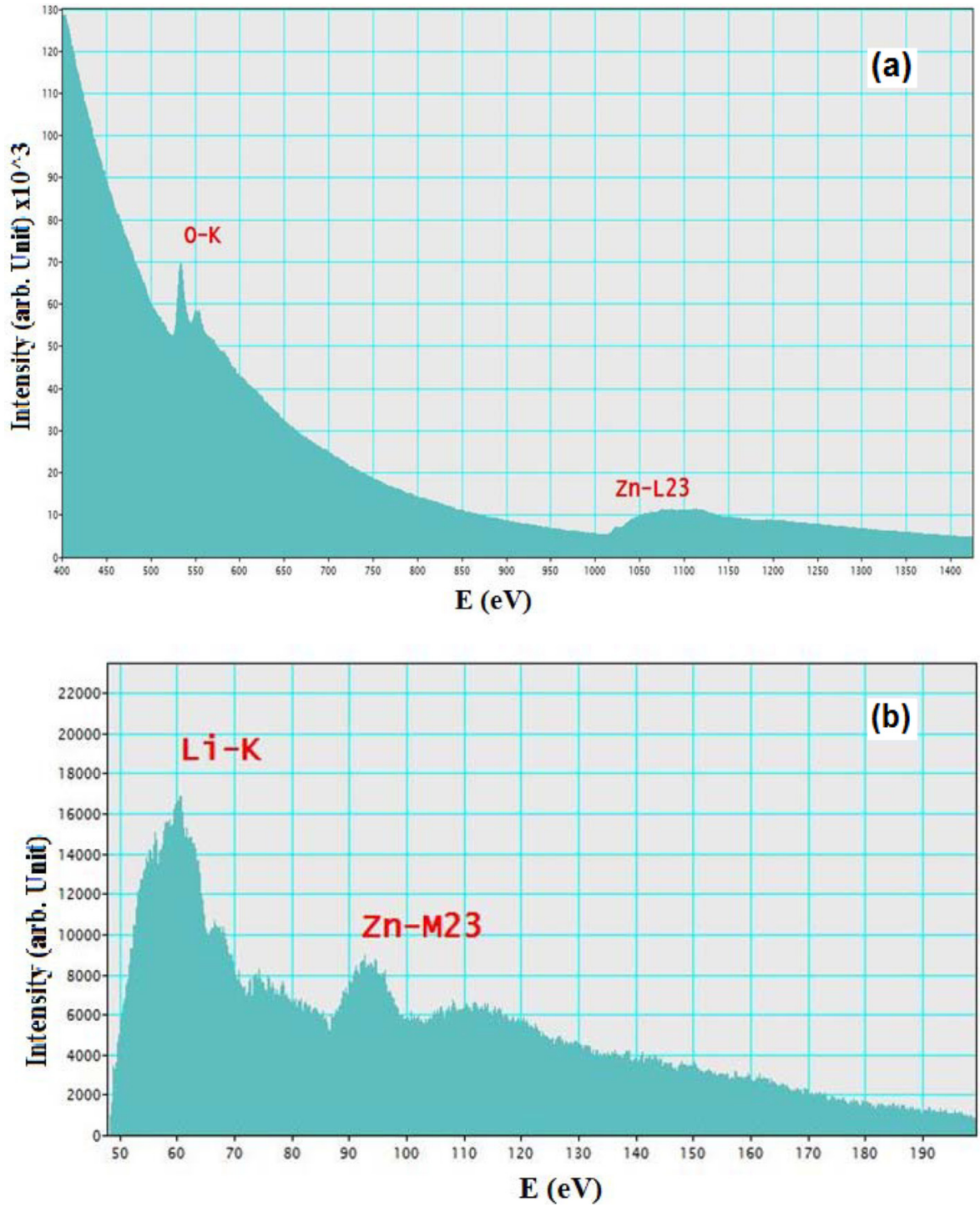

FIG. 4. (a) Zn-L23 edge and O-K edge EELS spectra (b) Li-K edge and Zn-M23 edge EELS spectra of $\mathrm{Zn}_{0.96} \mathrm{Li}_{0.04} \mathrm{O}$ nanoparticles. and 0.06$)$, where the percentage of substitutional $\mathrm{Li}$ are higher (we extracted via XPS ${ }^{31}$ ), have lower hole concentrations as compared to the ones where the percentage of interstitial $\mathrm{Li}$ are higher $(\mathrm{y}=0.02,0.08$, and 0.10 compositions). It is possible, as reported earlier, ${ }^{31}$ that interstitial $\mathrm{Li}$ are accompanied with $\mathrm{Zn}$ vacancies that may become a good source of hole concentrations. This is unusual in the sense that $\mathrm{Li}$ interstitials are generally understood to be $n$-type (electron) dopants. However, as discussed, ${ }^{25}$ the role of Li in this case is primarily to stabilize the formation of zinc vacancies by reducing their formation energies. These zinc

TABLE I. Hall measurements of $\mathrm{Zn}_{1-\mathrm{y}} \mathrm{Li}_{\mathrm{y}} \mathrm{O}(0.00 \leq \mathrm{y} \leq 0.10)$ nanoparticles.

\begin{tabular}{lcccc}
\hline \hline $\begin{array}{l}\text { Sample Comp } \\
\text { (Nominal) }\end{array}$ & $\begin{array}{c}\text { Carrier } \\
\text { type }\end{array}$ & $\begin{array}{c}\text { Resistivity } \\
(\mathrm{K} \Omega \text {-cm })\end{array}$ & $\begin{array}{c}\text { Mobility } \\
\left(\mathrm{cm}^{2} / \mathrm{v} . \mathrm{s}\right)\end{array}$ & $\begin{array}{c}\text { Carrier density } \\
\left(\mathrm{cm}^{-3}\right)\end{array}$ \\
\hline $\mathrm{ZnO}$ & $\mathrm{n}$ & 51.4 & 0.11 & $4.4 \mathrm{E}^{+15}$ \\
$\mathrm{Zn}_{0.98} \mathrm{Li}_{0.02} \mathrm{O}$ & $\mathrm{p}$ & 2.62 & 0.71 & $7.3 \mathrm{E}^{+17}$ \\
$\mathrm{Zn}_{0.96} \mathrm{Li}_{0.04} \mathrm{O}$ & $\mathrm{p}$ & 6.97 & 0.28 & $3.9 \mathrm{E}^{+17}$ \\
$\mathrm{Zn}_{0.94} \mathrm{Li}_{0.06} \mathrm{O}$ & $\mathrm{p}$ & 7.62 & 0.71 & $2.4 \mathrm{E}^{+17}$ \\
$\mathrm{Zn}_{0.92} \mathrm{Li}_{0.08} \mathrm{O}$ & $\mathrm{p}$ & 5.08 & 0.58 & $5.7 \mathrm{E}^{+17}$ \\
$\mathrm{Zn}_{0.90} \mathrm{Li}_{0.10} \mathrm{O}$ & $\mathrm{p}$ & 4.93 & 0.69 & $6.9 \mathrm{E}^{+17}$ \\
\hline \hline
\end{tabular}

vacancies, as is well understood, act as hole dopants with each $\mathrm{Zn}$ vacancy producing two holes. ${ }^{25,37}$ Here, we note that the hole concentrations that we have determined in our

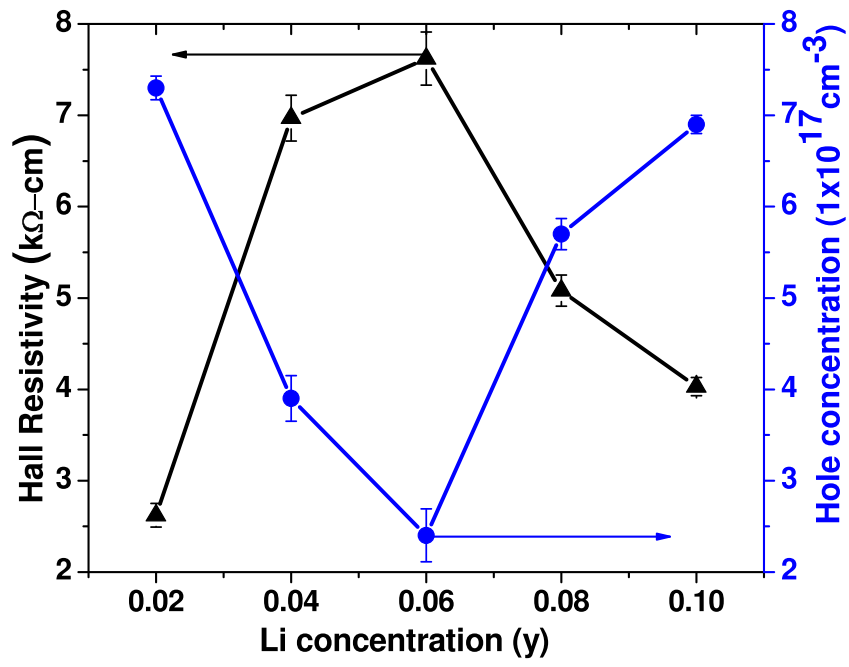

FIG. 5. Hall resistivity and $p$-type carrier concentration versus Li concentration for a series of $\mathrm{Zn}_{1-\mathrm{y}} \mathrm{Li}_{\mathrm{y}} \mathrm{O}(0.00 \leq \mathrm{y} \leq 0.10)$ nanoparticles. 
samples lie in the range $2.4 \times 10^{17} / \mathrm{cc}$ to $7.3 \times 10^{17} / \mathrm{cc}$. These findings are consistent with the discussion ${ }^{27}$ where such levels of hole concentration are shown as being sufficient to generate the indirect coupling of the electric dipole moments. The hole carriers concentration plays an important role in ferroelectricity and ferromagnetism in Li doped nanoparticles, which will be discussed in the following sections.

\section{Magnetic properties}

We have reported the room temperature $(\mathrm{RT} \sim 300 \mathrm{~K})$ ferromagnetic hysteresis loop data for this series of $\mathrm{Zn}_{1-\mathrm{y}} \mathrm{Li}_{\mathrm{y}} \mathrm{O}(0.00 \leq \mathrm{y} \leq 0.10)$ nanoparticles samples previously. ${ }^{31}$ We have suggested ${ }^{31}$ that the magnetic moment is larger in the region where the interstitial Li concentration is larger and vice versa. In the current study, we will investigate the effect of hole carriers on magnetic moment and possible mechanism in these non-magnetic oxide systems. Initially, here we observed an interesting correlation between interstitial Li and Hall resistivity (Table-I) with increasing magnetic moment for different Li compositions as summarized in Fig. 6(a). We noticed that $\mathrm{y}=0.02,0.08$, and 0.10 compositions are estimated to have a lower concentration of resistivity, while the magnetic moment is higher and vice
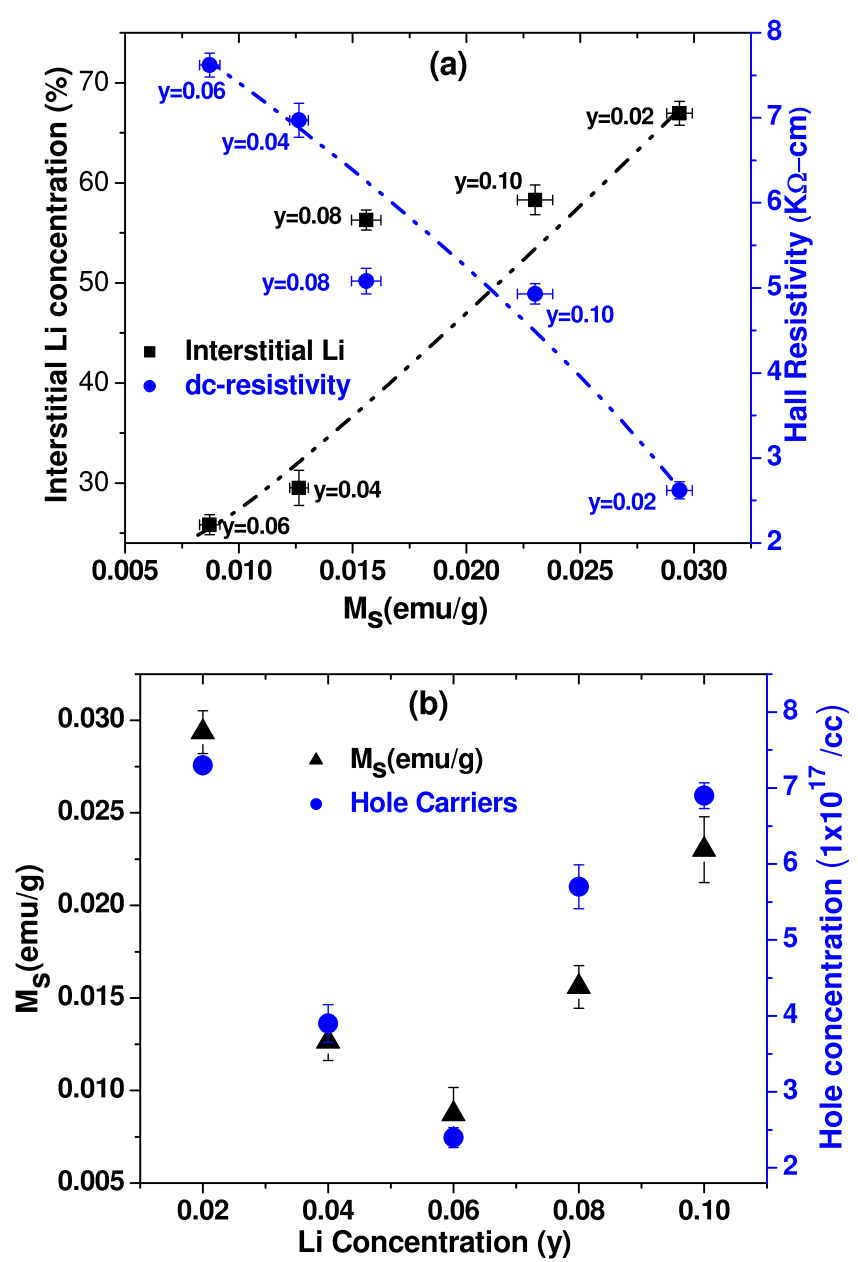

FIG. 6. (a) Interstitial Li defects and Hall resistivity versus saturation magnetization $\mathrm{M}_{\mathrm{S}}(300 \mathrm{~K})$ for different $\mathrm{Li}$ compositions (dotted lines for eyes guided) (b) saturation magnetization $\mathrm{M}_{\mathrm{S}}(300 \mathrm{~K})$ and Hole carrier concentration versus $\mathrm{Li}$ concentration for $\mathrm{Zn}_{1-\mathrm{y}} \mathrm{Li}_{\mathrm{y}} \mathrm{O}(0.00 \leq \mathrm{y} \leq 0.10)$ nanoparticles. versa for $\mathrm{y}=0.04$ and 0.06 samples. We found another intriguing correlation by plotting the saturation magnetization and hole concentration with increasing $\mathrm{Li}$ concentration as demonstrated in Fig. 6(b). The compositions $y=0.02,0.08$, and 0.10 are those where we have observed higher hole concentrations and have higher magnetic moments and vice versa for $\mathrm{y}=0.04$ and $\mathrm{y}=0.06$ compositions. So we can argue here that the magnetic moment arises due to hole carriers and saturation magnetization enhances due to higher hole concentrations. When we plotted the trend of hole concentrations and ferroelectric transition temperature $\left(\mathrm{T}_{\mathrm{c}}\right)$ (from our earlier report ${ }^{38}$ ) versus saturation magnetization for different Li compositions as shown in Fig. 7, we noticed that the compositions $2 \%, 8 \%$, and $10 \% \mathrm{Li}$ have a higher magnetic moment and ferroelectric transition temperature values due to higher hole concentrations and vice versa for $y=0.04$ and 0.06 samples. Now, we may suggest from the above data (Figs. 6 and 7) that the major role is played by hole carriers instead of interstitial Lithium. In our previous report, ${ }^{31}$ we have demonstrated that the magnetic moment arises in $\mathrm{Li}$ doped $\mathrm{ZnO}$ nanoparticles samples due to interstate Li. However, in this study, we inferred an important conclusion that hole carriers play an important role in mediating ferromagnetic interactions in these samples.

These are the most important result of the current study. As we reported previously, each interstitial Li defect will most likely be accompanied by a cationic vacancy, which in this case would be a vacant zinc site. Hence, higher hole concentrations are an indicator of more zinc vacancies which we recognize as the primary source of the magnetic moment. ${ }^{25,37}$ Our results however show that the $p$-type (hole) conductivity may support and strengthen the stabilization of long range order ferromagnetism in $\mathrm{Li}$ doped $\mathrm{ZnO}$ nanoparticles. We now conclude with a discussion of the possible mechanism that is relevant to our results. Yi et al. ${ }^{25}$ have demonstrated that cation vacancies can lead to ferromagnetism in $\mathrm{Li}$ doped $\mathrm{ZnO}$ thin films and have also concluded that such vacancies $\left(\mathrm{V}_{\mathrm{Zn}}\right)$ are normally very difficult to form but doping with appropriate elements (e.g., Li) can stabilize the cation vacancies and

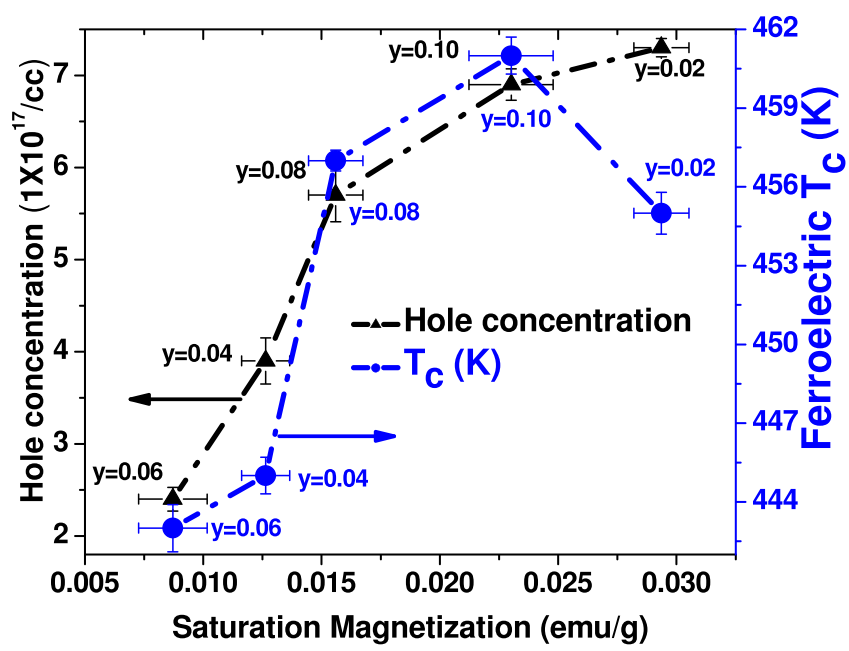

FIG. 7. Hole concentration and ferroelectric transition temperature $T_{c}$ versus saturation magnetization $\mathrm{M}_{\mathrm{S}}(300 \mathrm{~K})$ for $\mathrm{Zn}_{1-\mathrm{y}} \mathrm{Li}_{\mathrm{y}} \mathrm{O}(0.00 \leq \mathrm{y} \leq 0.10)$ nanoparticles. 
produce holes at the same time, which are required to mediate long range order ferromagnetism. ${ }^{25}$ They showed that Li occupies interstitial sites in $\mathrm{ZnO}$ at low concentration or low oxygen partial pressure, and substitutes $\mathrm{Zn}$ at moderate concentrations. ${ }^{25}$ At sufficiently high concentrations, the interstitial $\mathrm{Li}\left(\mathrm{Li}_{\mathrm{i}}\right)$ and substitutional $\mathrm{Li}\left(\mathrm{Li}_{\mathrm{Zn}}\right)$ defects form a stable defect complex which helps to lower the formation energy of $\mathrm{V}_{\mathrm{Zn}}$. Similarly, we observed ferromagnetism in $\mathrm{Zn}_{1-\mathrm{y}} \mathrm{Li}_{\mathrm{y}} \mathrm{O}$ nanoparticles that is attributed to magnetic moments of cation vacancies mediated by holes introduced by the $\mathrm{Li}$ and $\mathrm{Zn}$ defects. Yi et al ${ }^{25}$ further showed that $\mathrm{Li}_{\mathrm{i}}$ in the proximity of $\mathrm{Zn}$ vacancy lowers the formation energy of $\mathrm{V}_{\mathrm{Zn}}$ significantly and that the formation energy of a defect complex $\left(\mathrm{V}_{\mathrm{Zn}}+\mathrm{Li}_{\mathrm{i}}\right)$ is lower than the formation energy of a single $\mathrm{V}_{\mathrm{Zn}}$. Furthermore, if a $\mathrm{V}_{\mathrm{Zn}}$ is accompanied by a $\mathrm{Li}_{\mathrm{i}}$ defect and an additional Li substitutional defect, its formation energy can be further lowered. The formation energy of this defect complex $\left(\mathrm{V}_{\mathrm{Zn}}+\mathrm{Li}_{\mathrm{i}}+\mathrm{Li}_{\mathrm{Zn}}\right)$ becomes more negative at higher oxygen partial pressure. Therefore, they ${ }^{25}$ suggested that Li doping contributes to ferromagnetism in $\mathrm{ZnO}$ by lowering the formation energy $V_{Z n}$ and thereby stabilizing $V_{Z n}$ from which the magnetic moments originate. They calculated that each $\mathrm{V}_{\mathrm{Zn}}+\mathrm{Li}_{\mathrm{i}}+\mathrm{Li}_{\mathrm{Zn}}$ defect complex was found to contribute a magnetic moment of $1.1 \mu_{\mathrm{B}}$ which mainly comes from the $\mathrm{Zn}$ vacancy. These local magnetic moments can be coupled ferromagnetically by holes introduced by $\mathrm{Zn}$ vacancies and $\mathrm{Li}$ substitutional doping, resulting in a ferromagnetic $\mathrm{ZnO}$ at room temperature. Ferromagnetic coupling of these local moments could be mediated by the high concentration of holes introduced by $\mathrm{V}_{\mathrm{Zn}}$ resulting in the observed room temperature ferromagnetism.

While our results for the observation of ferromagnetism in $\mathrm{Zn}_{1-\mathrm{y}} \mathrm{Li}_{\mathrm{y}} \mathrm{O}(0.00 \leq \mathrm{y} \leq 0.10)$ nanoparticles highlight the role of these defects in stabilizing ferromagnetism presumably via the generation of zinc vacancies and the role of holes in mediating and promoting ferromagnetism, there is one aspect that appears at first glance to be at variance with the predictions. We have reported ${ }^{31}$ in the Li doped systems that the moment is generally higher for the higher interstitial concentrations while the models generally tend to emphasize substitutional $\mathrm{Li}$ in this role. In a complex situation such as this where a number of factors are playing a role we need to proceed with caution, hence we suggest the following explanation tentatively. While the $\mathrm{Li}$ interstitial is not expected to add to the hole concentration directly, its role in stabilizing the zinc vacancies and the defect complexes at higher $\mathrm{Li}$ concentrations has been reported. ${ }^{25}$ We have suggested ${ }^{31}$ that at these higher Li interstitial concentrations, the effect of formation of the ferromagnetic defect complex and stabilizing the zinc vacancy offsets the less favorable effects of the interstitial. This can only be understood in the scheme where the interstitial $\mathrm{Li}$ stabilizes the zinc vacancy that in turn lead to higher hole concentration. Hence the main role of the interstitial $\mathrm{Li}$ is to promote the formation of the zinc vacancy (i.e., high hole carriers) and its consequent effects on the ferromagnetism. Finally, we note that in accordance with some of the predictions, ferromagnetism is present even in the cases where the dominant contribution appears to be from substitutional Li. This highlights the general conclusion that $\mathrm{Li}$ in both configurations acts to support ferromagnetism by stabilizing the zinc vacancies; but for reasons discussed above, it is the hole carrier concentration that has a stronger positive effect on the ferromagnetism.

We found that ferromagnetism (FM) not only depends on the substitutional, and interstitial Li defects concentration present in each composition, but long range order ferromagnetism actually originates and couples due to hole concentrations. This is the reason of enhanced magnetic moment (e.g., in $y=0.02,0.08,0.10)$ due to higher hole carrier concentration. $\mathrm{Li}$ is a source for generating holes due to charge mismatch between $\mathrm{Zn}^{2+}$ and $\mathrm{Li}^{1+}$. By comparing our previous report ${ }^{31}$ (where we have emphasized FM produced due to $\mathrm{Zn}$ vacancy, i.e., more $\mathrm{Zn}$ vacancies due to more interstitial $\mathrm{Li}$ defects) and the current study, we finally concluded that FM enhanced and promotes due to hole carriers instead of interstitial $\mathrm{Li}$ defects. In other words, we may suggest that as the higher zinc vacancies are produced (i.e., when more Li ions occupy interstitial sites), more holes will be generated that correspond to the higher magnetic moment in these oxides systems.

\section{Ferroelectric measurements}

Room temperature ferroelectric hysteresis response (polarization versus electric field, $P$ - $E$ loops) was measured for a series of $\mathrm{Zn}_{1-\mathrm{y}} \mathrm{Li}_{\mathrm{y}} \mathrm{O}(0.00 \leq \mathrm{y} \leq 0.10)$ nanoparticles to understand the mechanism of ferroelectricity in oxide systems. No hysteresis was observed in the undoped $\mathrm{ZnO}$ and $2 \% \mathrm{Li}$ doped nanoparticles sample. An irregularly shaped loop was observed for $\mathrm{y}=0.04$ and a rather flat (regular) loop for $y=0.06$ (i.e., with smaller value of polarization) compositions are presented in Fig. 8(a). It can be seen that normal hysteresis loops, even unsaturated, are observed in $\mathrm{y}=0.08$ and $\mathrm{y}=0.10$ samples as demonstrated in Fig. 9(b).
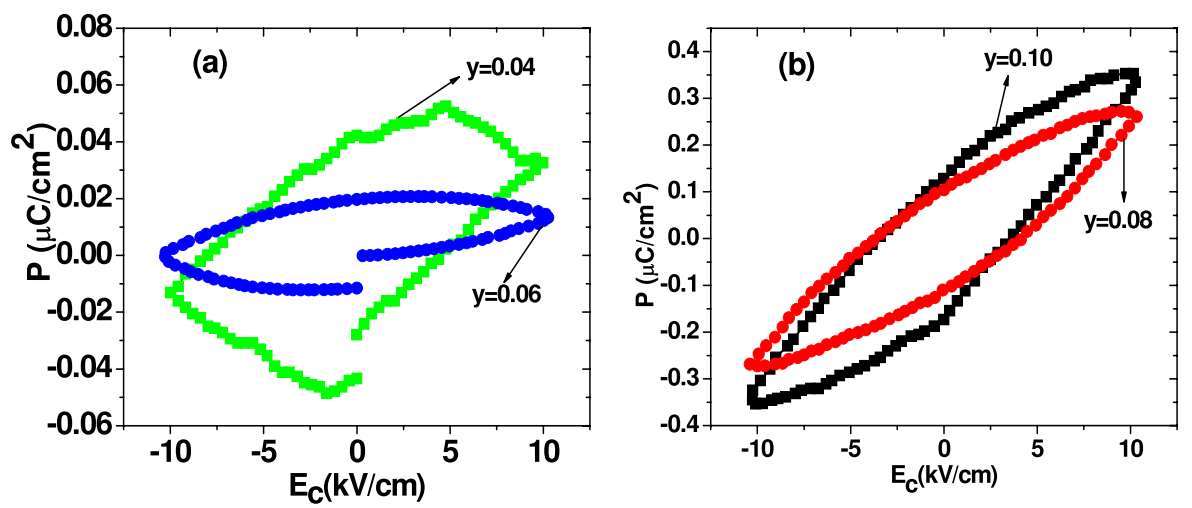

FIG. 8. Room temperature ferroelectric polarization versus electric field $(P-E)$ hysteresis loop of $\mathrm{Zn}_{1-\mathrm{y}} \mathrm{Li}_{\mathrm{y}} \mathrm{O}$ nanoparticles (a) $\mathrm{y}=0.04$ and $\mathrm{y}=0.06$ (b) $\mathrm{y}=0.08$ and $\mathrm{y}=0.10$. 


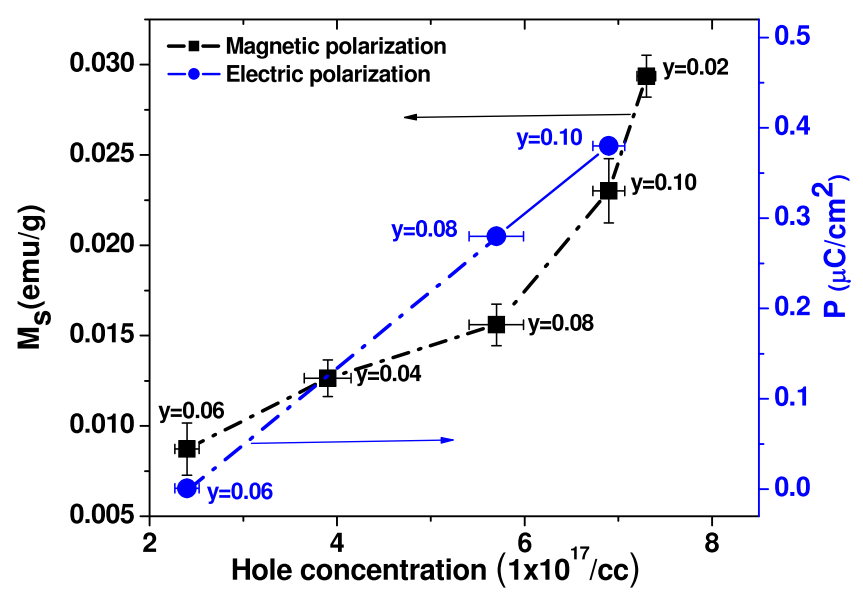

FIG. 9. Saturation magnetization and electric polarization versus Hole concentrations for varying $\mathrm{Li}$ concentrations of $\mathrm{Zn}_{1-\mathrm{y}} \mathrm{Li}_{\mathrm{y}} \mathrm{O}(0.00 \leq \mathrm{y} \leq 0.10)$ nanoparticles samples.

Hence it does appear from this data that there is a critical concentration for Li to generate normal ferroelectric behavior, which is about at least $6 \%$. These $P-E$ loops are not fully saturated due to leakage current effects in pelletized samples. The measured values of maximum polarization $\left(P_{\max }\right)$ are $0.28 \mu \mathrm{C} / \mathrm{cm}^{2}$ and $0.38 \mu \mathrm{C} / \mathrm{cm}^{2}$ for $\mathrm{y}=0.08$ and 0.10 compositions, respectively. The coercivity $\left(E_{C}\right)$ value for $\mathrm{y}=0.08$ and 0.10 samples are $2.5 \mathrm{kV} / \mathrm{cm}$ and $2.8 \mathrm{kV} / \mathrm{cm}$, respectively. The remnant polarization of $\mathrm{Zn}_{0.92} \mathrm{Li}_{0.08} \mathrm{O}$ and $\mathrm{Zn}_{0.90} \mathrm{Li}_{0.1} \mathrm{O}$ are $0.11 \mu \mathrm{C} / \mathrm{cm}^{2}$ and $0.15 \mu \mathrm{C} / \mathrm{cm}^{2}$ calculated from $P-E$ data. These values are comparable with the results of previously $\mathrm{ZnO}: \mathrm{Li}$ films, ${ }^{22}$ nanorods, ${ }^{23}$ and ceramics. ${ }^{14,20}$ In reports, ${ }^{14,20,22,23}$ no $P$ - $E$ hysteresis loop was observed for the un-doped $\mathrm{ZnO}$ system or with low Li dope concentrations. But hysteresis was observed for certain $\mathrm{Li}$ concentrations, e.g., $7.5 \% \mathrm{Li}{ }^{39}$ indicating that the ferroelectricity in $\mathrm{ZnO}: \mathrm{Li}$ systems are caused by the Li concentration.

By comparing ferroelectric saturation polarization with hole carrier concentration, we noticed that for $\mathrm{y}=0.08$ and 0.10 compositions, saturation polarizations were $0.28 \mu \mathrm{C} / \mathrm{cm}^{2}$ and $0.38 \mu \mathrm{C} / \mathrm{cm}^{2}$, respectively, corresponding to the higher carrier concentration $\left(5.7 \times 10^{17} / \mathrm{cc}\right.$ and $\left.6.9 \times 10^{17} / \mathrm{cc}\right)$ and vice versa for $\mathrm{y}=0.04$ and 0.06 compositions. We noticed an anomaly for $\mathrm{y}=0.02$ sample; the carrier density was $7.3 \times 10^{17} \mathrm{~cm}^{-3}$ but it might be that the net interaction/coupling of these electric dipole-dipole was not sufficient for generating ferroelectric hysteresis loop. We have inferred from the above data that the compositions $\mathrm{y}=0.08$ and 0.10 , which have higher ferroelectric transition temperature $\left(\mathrm{T}_{\mathrm{c}}\right)^{38}$ and electric saturation polarization, are those having higher hole concentrations as demonstrated in Figs. 7 and 9. We may argue that hole carriers are the best candidates for coupling ferroelectric $\mathrm{T}_{\mathrm{c}}$ and net electric moment. Hence, higher hole concentration $\left(\sim 5.7 \times 10^{17} \mathrm{~cm}^{-3}\right)$ is sufficient not only for attaining well above room temperature $T_{c}$ but suitable for achieving well defined ferroelectric saturation polarization. Another interesting correlation, regarding ferroelectric and ferromagnetic behavior is, higher magnetic and electric saturation polarization for $\mathrm{y}=0.08$ and 0.10 compositions, and both parameters are lower for $\mathrm{y}=0.04$ and 0.06 samples as plotted in Fig. 9. From this data, we suggest an interesting correlation that ferroelectric and ferromagnetic behavior in $\mathrm{Li}$ doped $\mathrm{ZnO}$ nanoparticles system appears due to $p$-type charge carriers. The net coupling effects of electric dipoles depend on the critical concentration of hole carriers in these oxides based semiconducting nanoparticles as were reported theoretically. ${ }^{27} \mathrm{We}$ demonstrate here the remnant polarization/magnetization and coercive field that are applied in the field of nano-storage and nano-memories devices.

The origin of this ferroelectric behavior could be explained on the basis of the ionic radii difference between the host $\mathrm{Zn}^{2+}(0.074 \mathrm{~nm})$ and impurity $\mathrm{Li}^{1+}(0.060 \mathrm{~nm})$ ions. Due to this ionic size difference, $\mathrm{Li}^{1+}$ ions can occupy offcentered positions, which lead to permanent local electric dipoles and thereby inducing ferroelectric behavior. ${ }^{14,26}$ Glinchuk et al. ${ }^{27,29}$ proposed that ferroelectricity might appear due to indirect interactions of dipoles, formed by the Li off centered impurities, via free charge carriers (i.e., hole in Li case). They ${ }^{27}$ estimated that the concentration of hole carriers like $10^{17} \mathrm{~cm}^{-3}$ was sufficient for ferroelectricity in $\mathrm{Li}$ doped $\mathrm{ZnO}$ systems. Here, we briefly discuss the physical model for indirect coupling of the electrical dipoles in $\mathrm{Zn}_{1-\mathrm{y}} \mathrm{Li}_{\mathrm{y}} \mathrm{O}$ and its relevance to our data. These $\mathrm{Li}$ doped $\mathrm{ZnO}$ nanoparticles reveal hysteresis loops and spontaneous polarization. It is believed that the main constituent of the ferroelectricity in these oxides based nanoparticles systems is the difference in the ionic radii of the host dielectric and impurity cations, yielding the off-center shift of impurity ion position, generating dipole moment. ${ }^{14,26}$ The physical reasons for ferroelectricity to occur in the $\mathrm{Li}$ doped $\mathrm{ZnO}$ nanoparticles, the indirect dipole interaction via charge carriers (i.e., hole in Li case); forming overall spontaneous polarization is necessarily required. ${ }^{27}$ In the case of impurity induced ferroelectricity, the impurities should form dipoles that are able to orient and interact with each other for long range order ferroelectricity at room temperature. In our case, such interactions occur via free charge carriers (e.g., hole) of a host crystal. The necessary condition to obtain a dipole from Li defects is the substantial difference in the ionic radii between the impurity and the host cations. The above features are possible only if the impurity ionic radius is smaller than that of a host cation. However, at high temperatures, the thermal energy exceeds the mean interactions between dipoles so that the long range order disappears and the above system becomes paraelectric. The ferroelectric ordering by indirect interaction of impurity (e.g., Li) dipoles via free charge carriers consists of holding the orientation of dipoles due to carriers (e.g., hole) scattering of them. ${ }^{27}$

The main question here is, what makes the dipoles become ferroelectrically ordered at room temperature. In well know perovskite ferroelectric systems such as Li doped $\mathrm{KTaO} 3$, the mechanism of the ferroelectric ordering and net coupling is the indirect interaction of the impurity dipoles via soft phonon mode of host dielectric. ${ }^{40}$ However, a new possible mechanism ${ }^{26,27}$ of ferroelectricity in the host semiconducting substances, e.g., $\mathrm{ZnO}, \mathrm{CdTe}, \mathrm{CdS}$, and $\mathrm{CdSe}$ with a non-perovskite structure has been considered, namely, the Ruderman-Kittel-Kasuya-Yosida (RKKY) like indirect interaction of impurity dipoles via free charge carriers. The semiconducting carrier concentration of $10^{17} / \mathrm{cc}$ is sufficient 
for RKKY interactions, as has been proposed theoretically. ${ }^{27,28}$ Recently, in diluted magnetic semiconductors, the ferromagnetism appeared due to RKKY indirect coupling between $\mathrm{d}$-shell localized magnetic moments mediated by the induced spin-polarization in a hole carrier system. ${ }^{41}$ Since it is not excluded that the off-center ion (e.g., Mn) can have both spin and electric dipole moments, the (Ga,Mn)As system could be the candidates for the realization of longrange order ferromagnetism due to RKKY interaction, and for ferroelectricity due to carrier mediated dipole-dipole interaction. ${ }^{42}$ This means that the interaction via hole charge carriers can make the Li doped $\mathrm{ZnO}$ system as a multiferroic as $(\mathrm{Ga}, \mathrm{Mn}) \mathrm{As}$ systems. The experimental investigation shows that the temperature of ferromagnetic phase transition of (Ga,Mn)As is $\mathrm{T}_{C}=110 \mathrm{~K}$ (Ref. 43) and $\mathrm{T}_{C}=173 \mathrm{~K}$ (Ref. 44) has been reported, due to the randomness of the $\mathrm{Mn}$ ions distribution. However, in our $\mathrm{Zn}_{1-y} \mathrm{Li}_{\mathrm{y}} \mathrm{O}$ nanoparticles system, we have reported above room temperature ferromagnetic transition temperature. ${ }^{31}$ Whereas we have investigated a ferroelectric transition temperature range $442 \mathrm{~K}-466 \mathrm{~K}$ to paraelectric. ${ }^{38}$ Now, by comparing the ferroelectric and ferromagnetic properties, we may confidently suggest that our $\mathrm{Zn}_{1-\mathrm{y}} \mathrm{Li}_{\mathrm{y}} \mathrm{O}$ system is better than $(\mathrm{Ga}, \mathrm{Mn}) \mathrm{As}$ system.

It has been proposed ${ }^{28}$ that the indirect interaction of impurity dipoles via conduction electrons of a host semiconductor has the modified RKKY ${ }^{27-29}$ form with an amplitude

$$
J(r)=\frac{m^{*} V^{2} a_{0}^{2}}{8 \pi^{3} \hbar^{2}} k_{f}^{2} .
$$

Here $m^{*}, V$, and $a_{0}$, are the carrier effective mass, unit cell volume, and dipole-carrier interaction constant, respectively. Since the Fermi wave vector $\left(k_{f}\right)$ is dependent on the carrier concentration in the usual way $\left(k_{f} \sim \mathrm{n}^{1 / 3}\right)$, the strength of the indirect interaction is expected to increase in carrier (hole) concentration. It has been reported that ferroelectricity occurs above a critical $\mathrm{Li}$ concentration of about $5 \%$ in a bulk system. ${ }^{14,45}$ We suggest that in our data, the increase of electric polarization with increasing hole concentrations, rather than with increasing $L i$ concentrations, is related to the increase in the Fermi wave vector which in turn strengthens the indirect interaction between the electric dipoles, according to Eq. (1).

\section{CONCLUSION}

High resolution transmission electron microscopic analysis confirmed the wurtzite crystalline structure. Diffraction patterns showed the presence of the single phase. EELS detected the low atomic number Li ions significantly in samples. Homogeneous distribution of $\mathrm{Li}$ in $\mathrm{ZnO}$ structure was investigated via mapping micrographs. Li doped nanoparticles showed $p$-type conductivity character in these dilute non-magnetic semiconductors. Non-monotonic trend of hole carriers was observed with increasing Li content. Thus, our results point towards the critical role of hole concentrations in stabilizing the ferromagnetism in doped nanoparticles. Ferroelectric $P-E$ hysteresis loops were observed at room temperature for higher concentration of $\mathrm{Li}$ (i.e., $\mathrm{y}>0.04$ ) doped samples. The ferroelectricity in doped samples is not the inherent but is induced by the introduction of $\mathrm{Li}$ ions. The main physical mechanism of ferroelectricity may be due to an indirect interaction between Li impurity formed dipoles and coupling via hole carriers. Our experimental results show that well defined ferroelectric hysteresis loops are obtained for hole concentration around $5.7 \times 10^{17} \mathrm{~cm}^{-3}$. Hall measurements show that the hole concentrations are higher where magnetic moment and electric saturation polarization is higher. The ferroelectric saturation polarization is higher for $8 \%$ and $10 \% \mathrm{Li}$, where we have higher $p$-type carrier concentration and vice versa for $0.04 \%$ and $0.06 \%$. We emphasize here that hole carriers play a role for ferromagnetic and ferroelectric hysteresis and spontaneous polarization in $\mathrm{Li}$ doped $\mathrm{ZnO}$ nanoparticles. Our results fulfill the requirements of multiferroic technology and play a crucial role in enhancing the data storage capacity for memory devices in future.

\section{ACKNOWLEDGMENTS}

S. U. Awan and S. K. Hasanain particularly acknowledge Higher Education Commission (HEC) of Pakistan. Funding for this research work was provided under "5000 Indigenous Ph.D. fellowship program (HEC-Pin-No. 041-211772 P-108)" and the project "Development and Study of Magnetic Nanostructures" of HEC.

${ }^{1}$ C. Chappert, A. Fert, and F. Nguyen Van Dau, Nature Mater. 6, 813 (2007).

${ }^{2}$ S. Cheong and M. Mostovoy, Nature Mater. 6, 13 (2007).

${ }^{3}$ M. Fiebig, T. Lottermoser, D. Fröhlich, A. V. Goltsev, and R. V. Pisarev, Nature 419, 818 (2002); N. A. Spaldin and M. Fiebig, Science 309, 391 (2005).

${ }^{4}$ N. A. Hill, J. Phys. Chem. B 104, 6694 (2000); H. Schmid, Ferroelectrics 162, 317 (1994)

${ }^{5}$ H. Schmid, Ferroelectrics 9, 221 (1999).

${ }^{6}$ B. Bhushan, A. Basumallick, S. K. Bandopadhyay, N. Y. Vasanthacharya, and D. Das, J. Phys. D: Appl. Phys. 42, 065004 (2009); W. Eerenstein, N. D. Mathur, and J. F. Scott, Nature 442, 759 (2006); F. Zavaliche, T. Zhao, H. Zheng, F. Straub, M. P. Cruz, P. L. Yang, D. Hao, and R. Ramesh, Nano Lett. 7, 1586 (2007).

${ }^{7}$ E. Ascher, H. Rieder, H. Schmid, and H. Stoössel, J. Appl. Phys. 37, 1404 (1966).

${ }^{8}$ Y. Huang, Z. J. Cao, Y. Y. Sun, Y. Y. Xue, and C. W. Chu, Phys. Rev. B 56, 2623 (1997).

${ }^{9}$ W. Brixel, J.-P. Rivera, A. Steiner, and H. Schmid, Ferroelectrics 79, 201 (1988).

${ }^{10}$ Y. Yang, L. Y. Zhiguang Wang, J.-F. Li, J. Das, A. L. Geiler, A. Yang, Y. Chen, V. G. Harris, and D. Viehland, J. Appl. Phys. 109, 034102 (2011).

${ }^{11}$ D. K. Hwang, S. H. Kang, J. H. Lim, E. J. Yang, J. Y. Oh, J. H. Yang, and S. J. Park, Appl. Phys. Lett. 86, 222101 (2005); H. Ohta, M. Orita, M. Hirano, and H. Hosono, J. Appl. Phys. 89, 5720 (2001); H. Ohta, H. Mizoguchi, M. Hirano, S. Narushima, T. Kamiya, and H. Hosono, ibid. 82, 823 (2003); C. H. Park, I. S. Jeong, J. H. Kim, and S. Im, ibid. 82, 3973 (2003); Ya. I. Alivov, J. E. Van Nostrand, D. C. Look, M. V. Chukichev, and B. M. Ataev, ibid. 83, 2943 (2003).

${ }^{12}$ A. Tsukazaki, M. Kubota, A. Ohtomo, T. Onuma, K. Ohtani, H. Ohno, S. F. Chichibu, and M. Kawasaki, Jpn. J. Appl. Phys., Part 2 44, L643 (2005).

${ }^{13}$ S. Limpijumnong, S. B. Zhang, S.-H. Wei, and C. H. Park, Phys. Rev. Lett. 92, 155504 (2004); C. H. Park, S. B. Zhang, and S. H. Wei, Phys. Rev. B 66, 073202 (2002); D. C. Look, G. M. Renlund, R. H. Burgener, and J. R. Sizelove, App. Phys. Lett. 85, 5269 (2004); Y. R. Ryu, T. S. Lee, and H. W. White, Appl. Phys. Lett. 83, 87 (2003); A. V. Singh, R. M. Mehra, A. Wakahara, and A. Yoshida, J. Appl. Phys. 93, 396 (2003). 
${ }^{14}$ A. Onodera, N. Tamaki, Y. Kawamura, T. Sawada, and H. Yamashita, Jpn. J. Appl. Phys., Part 1 35, 5160 (1996).

${ }^{15}$ Y. Kanai, Jpn. J. Appl. Phys., Part 1 30, 703 (1991).

${ }^{16}$ H. E. Ruda, Widegap II-VI Compounds for Opto-Electronics Applications (Chapman and Hall, London, 1992), p. 281.

${ }^{17}$ Y. J. Zeng, Z. Z. Ye, W. Z. Xu, D. Y. Li, J. G. Lu, L. P. Zhu, and B. H. Zhao, Appl. Phys. Lett. 88, 062107 (2006); Y. J. Zeng, Z. Z. Ye, J. G. Lu, W. Z. Xu, L. P. Zhu, and B. H. Zhao, ibid. 89, 042106 (2006); J. S. Lee, S. N. Cha, J. M. Kim, H. W. Nam, S. H. Lee, W. B. Ko, K. L. Wang, J. G. Park, and J. P. Hong, Adv. Mater. 23, 4183 (2011); S. Majumdar and P. Banerji, Appl. Phys. A 100, 487 (2010); S. Tsai, M. Hon, and Y. Lu, J. Phys. Chem. C 115, 10252 (2011); Y. Zeng, Z. Ye, W. Xu, L. Chen, D. Li, L. Zhu, B. Zhao, and Y. Hu, J. Cryst. Growth 283, 180 (2005).

${ }^{18}$ S. Chawla, K. Jayanthi, and R. K. Kotnala, Phys. Rev. B 79(12), 125204 (2009).

${ }^{19}$ B. E. Jun, Y. S. Kim, B. K. Moon, B. C. Choi, and J. H. Jeong, J. Korean Phys. Soc. 53, 1655 (2008).

${ }^{20}$ N. Tamaki, A. Onodera, K. Jin, and H. Yamashita, Jpn. J. Appl. Phys., Part 1 36, 6008 (1997); A. Onodera, K. Yoshio, H. Satoh, H. Yamashita, and N. Sakagami, ibid. 37, 5315 (1998); A. Onodera, N. Tamaki, T. Sawada, and H. Yamashita, J. Korean Phys. Soc. 29, S668 (1996); N. Tamaki, A. Onodera, Y. Kawamura, T. Sawada, N. Sakagami, K. Jin, H. Satoh, and H. Yamashita, ibid. 32, S11 (1998).

${ }^{21}$ A. Onodera, K. Yoshio, H. Satoh, T. Takamac, M. Fujita, and H. Yamashita, Ferroelectrics 230, 163 (1999).

${ }^{22}$ J. S. Kim, H. J. Lee, H. J. Seog, and I. 1. 1. Won Kim, J. Korean Phys. Soc. 58, 640 (2011); J. Nagaraju Dhananjay and S. B. Krupanidhia, J. Appl. Phys. 101, 104104 (2007); J. Nagaraju and S. B. Krupanidhia Dhananjay, ibid. 99, 034105 (2006); X. S. Wang, Z. C. Wu, J. F. Webb, and Z. G. Liu, Appl. Phys. A 77, 561 (2003); C. W. Zou, M. Li, H. J. Wang, M. L. Yin, C. S. Liu, L. P. Guo, D. J. Fu, and T. W. Kang, Nucl. Instrum. Methods Phys. Res. B 267, 1067 (2009); P. Roy Choudhury, J. Nagaraju Dhananjay, and S. B. Krupanidhi, J. Phys. D: Appl. Phys. 39, 2664 (2006); Y. J. Zhang, J. B. Wang, X. L. Zhong, Y. C. Zhou, X. L. Yuan, and T. Sekiguchi, Solid State Commun. 148, 448 (2008).

${ }^{23}$ M. K. Gupta and B. Kumar, J. Alloys Compd. 509, L208 (2011).

${ }^{24}$ S. Chawla, K. Jayanthi, and R. K. Kotnala, J. Appl. Phys. 106, 113923 (2009).

${ }^{25}$ J. B. Yi, C. C. Lim, G. Z. Xing, H. M. Fan, L. H. Van, S. L. Huang, K. S. Yang, X. L. Huang, X. B. Qin, B. Y. Wang, T. Wu, L. Wang, H. T. Zhang, X. Y. Gao, T. Liu, A. T. S. Wee, Y. P. Feng, and J. Ding, Phys. Rev. Lett. 104, $137201(2010)$
${ }^{26}$ R. Weil, R. Nkum, E. Muranevich, and L. Benguigui, Phys. Rev. Lett. 62, 2744 (1989); B. A. Bunker Quazi and T. Islam, Phys. Rev. Lett. 59, 2701 (1987).

${ }^{27}$ M. D. Glinchuk, E. V. Kirichenko, V. A. Stephanovich, and B. Y. Zaulychny, J. Appl. Phys. 105, 104101 (2009).

${ }^{28}$ V. A. Stephanovich, M. D. Glinchuk, and R. Blinc, Eur. Phys. Lett. 83, 37004 (2008).

${ }^{29}$ B. E. Vugmeister and M. D. Glinchuk, Rev. Mod. Phys. 62, 993 (1990).

${ }^{30}$ R. Blinc, M. D. Glinchuk, and V. A. Stephanovich, Ferroelectrics 391, 108 (2009).

${ }^{31}$ S. U. Awan, S. K. Hasanain, M. F. Bertino, and G. H. Jaffari, J. Appl. Phys. 112, 103924 (2012).

${ }^{32}$ D. R. G. Mitchell, Ultramicroscopy 108, 367 (2008).

${ }^{33}$ X. G. Xu, C. Li, J. X. Li, U. Kol, F. Wu, and G. Chen, J. Phys. Chem. B 107, 11648 (2003).

${ }^{34}$ P. Sharma, A. Gupta, K. V. Rao, F. J. Owens, R. Sharma, R. Ahuja, J. M. O. Guillen, B. Johansson, and G. A. Gehring, Nature Mater. 2, 673 (2003).

${ }^{35}$ B. Wang, J. Min, Y. Zhao, W. Sang, and C. Wang, App. Phys. Lett. 94, 192101 (2009).

${ }^{36}$ K. C. Chiu, Y. W. Kao, and J. H. Jeanw, J. Am. Ceram. Soc. 93, 1860 (2010); D. C. Look and B. Claflin, Phys. Status Solidi B 241, 624 (2004).

${ }^{37}$ H.-X. Gao and J.-B. Xia, J. Appl. Phys. 111, 093902 (2012).

${ }^{38}$ S. U. Awan, S. K. Hasanain, G. Hassnain Jaffari, and Z. Mehmood, Appl. Phys. Lett. 104, 222906 (2014).

${ }^{39}$ Z. C. Wu, X. M. Zhang, J.-M. Liu, Q. C. Li, X. Y. Chen, J. Yin, N. Xu, and Z. G. Liu, Ferroelectrics 252, 265 (2001).

${ }^{40}$ V. Trepakov, F. Smutny, V. Vikhnin, V. Bursian, L. Sochava, L. Jastrabik, and P. Syrnikov, J. Phys.: Condens. Matter 7, 3765 (1995); H. Yokota, T. Oyama, and Y. Uesu, Phys. Rev. B 72, 144103 (2005).

${ }^{41}$ T. Dietl, A. Haury, and Y. M. d'Aubigne, Phys. Rev. B 55, R3347 (1997).

${ }^{42}$ K. Vladar and A. Zawadowski, Phys. Rev. B 28, 1564 (1983).

${ }^{43}$ H. Ohno, Science 281, 951 (1998).

${ }^{44}$ T. Jungwirth, K. Y. Wang, J. Mašek, K. W. Edmonds, J. König, J. Sinova, M. Polini, N. A. Goncharuk, A. H. MacDonald, M. Sawicki, A. W. Rushforth, R. P. Campion, L. X. Zhao, C. T. Foxon, and B. L. Gallagher, Phys. Rev. B 72, 165204 (2005).

${ }^{45}$ A. Onodera, Ferroelectrics 267, 131 (2002). 